\title{
A new model for predicting irreducible water saturation in tight gas reservoirs
}

\author{
Yu-Liang Su ${ }^{1} \cdot$ Jin-Gang Fu ${ }^{1} \cdot$ Lei Li $^{1} \cdot$ Wen-Dong Wang ${ }^{1} \cdot$ Atif Zafar $^{1,2} \cdot$ Mian Zhang ${ }^{3} \cdot$ Wei-Ping Ouyang ${ }^{3}$
}

Received: 12 June 2019 / Published online: 21 February 2020

(c) The Author(s) 2020

\begin{abstract}
The irreducible water saturation $\left(S_{\text {wir }}\right)$ is a significant parameter for relative permeability prediction and initial hydrocarbon reserves estimation. However, the complex pore structures of the tight rocks and multiple factors of the formation conditions make the parameter difficult to be accurately predicted by the conventional methods in tight gas reservoirs. In this study, a new model was derived to calculate $S_{\text {wir }}$ based on the capillary model and the fractal theory. The model incorporated different types of immobile water and considered the stress effect. The dead or stationary water (DSW) was considered in this model, which described the phenomena of water trapped in the dead-end pores due to detour flow and complex pore structures. The water film, stress effect and formation temperature were also considered in the proposed model. The results calculated by the proposed model are in a good agreement with the experimental data. This proves that for tight sandstone gas reservoirs the $S_{\text {wir }}$ calculated from the new model is more accurate. The irreducible water saturation calculated from the new model reveals that $S_{\text {wir }}$ is controlled by the critical capillary radius, DSW coefficient, effective stress and formation temperature.
\end{abstract}

Keywords Fractal theory $\cdot$ Stress dependence effect $\cdot$ Capillary model $\cdot$ Tight sandstone gas reservoir $\cdot$ Irreducible water saturation

\section{Introduction}

The irreducible water saturation $\left(S_{\text {wir }}\right)$ is one of the key parameters of gas-water two-phase flow in tight gas reservoirs. It plays an important role in reservoir evaluation, productivity prediction and hydrocarbon reserve estimation in tight sandstone gas reservoirs. $S_{\text {wir }}$ is the ratio of the volume of immobile water adsorbed on the rock surface, remained

Edited by Yan-Hua Sun

Yu-Liang Su

sylupc@gmail.com

$\triangle$ Jin-Gang Fu

fujgupc@gmail.com

1 School of Petroleum Engineering, China University of Petroleum (East China), Qingdao 266580, Shandong, China

2 Department of Petroleum Technology, University of Karachi, Karachi, Pakistan

3 Changqing Downhole Technology Company, Chuanqing Drilling Engineering Co. Ltd, CNPC, Xi' an 710018, Shaanxi, China in micropores and trapped in the dead-end pores to the total pore volume of the reservoir rocks (Cheng et al. 2017).

At present, $S_{\text {wir }}$ can be obtained from the nuclear magnetic resonance (NMR) experiment (Borgia et al. 1996), weighing method (Coskun and Wardlaw 1995; Taktak et al. 2011), mercury injection capillary pressure method (Bear et al. 2011; Zhang et al. 2017) and semi-permeable diaphragm capillary pressure method (Coskun and Wardlaw 1995; Taktak et al. 2011). However, these methods have some disadvantages. The applied interpretation method of NMR data is to split the signal into a fast relaxing part and a slow relaxing part. The first is interpreted as bound water, and the later as free fluid (Looyestijn 2001). Generally, $T_{2 \text { cutoff }}$ is the split between the movable fluid and the immovable fluid in the NMR $T_{2}$ distributions. The $T_{2 \text { cutoff }}$ values obtained by different ways will lead to different calculation results of $S_{\text {wir }}$ in NMR experiments. It is very difficult to choose a suitable centrifugal force for low-permeability tight core samples in the weighing method. Similarly, the appropriate choice of the lower limit of capillary radius is the key to the success in mercury injection capillary pressure experiment. The test time of semi-permeable diaphragm experiment is too long. In addition, due to the limited bearing capacity of 
the separator, this method cannot obtain a complete capillary pressure curve. Pore network modeling and other methods can also be used to research the $S_{\text {wir }}$ (Goral et al. 2018; Zhu et al. 2019); however, none of the above experimental methods can obtain $S_{\text {wir }}$ under reservoir conditions.

Previous studies suggested that the irreducible water was simply considered as water in sub-capillary pores and water film in theoretic models. The water in sub-capillary pores is unable to flow because the displacement pressure cannot overcome the capillary force. Assuming the rock surface is hydrophilic, the water film (WF) is the water trapped on the pore wall by molecular forces. The thickness of the water film is not constant which is mainly affected by the radius of pore throat, fluid properties, pressure difference, temperature and other conditions ( $\mathrm{Li}$ et al. 2015). In actual tight gas reservoir conditions, the structure of the porous media is complex, especially in the heterogeneous reservoir. Civan pointed out that fluids in some disconnected pores including small corners and dead-end pores may be trapped in dead or stationary fluid regions (Civan 2001). Therefore, some immovable water called the dead or stationary water (DSW) remained in the special pores and it cannot be able to flow under flow conditions. A schematic figure of the capillary model of flow in the porous media considering the effects of dead-end pores is presented in Fig. 1. The dead-end pore system is completely filled with immobile water due to detour flow effect and special pore structure. This part of the immobile water cannot flow due to it is located in disconnected pores, and there no channel to allow it flow; however, it can be squeezed less under the effective stress condition. At present, there is no model available which incorporates the impact of special immobile water of DSW.

A new $S_{\text {wir }}$ model was established by deriving tube capillary model based on the fractal theory under stress effect and considering the influence of dead or stationary water, water film, pressure gradient and temperature. This proposed

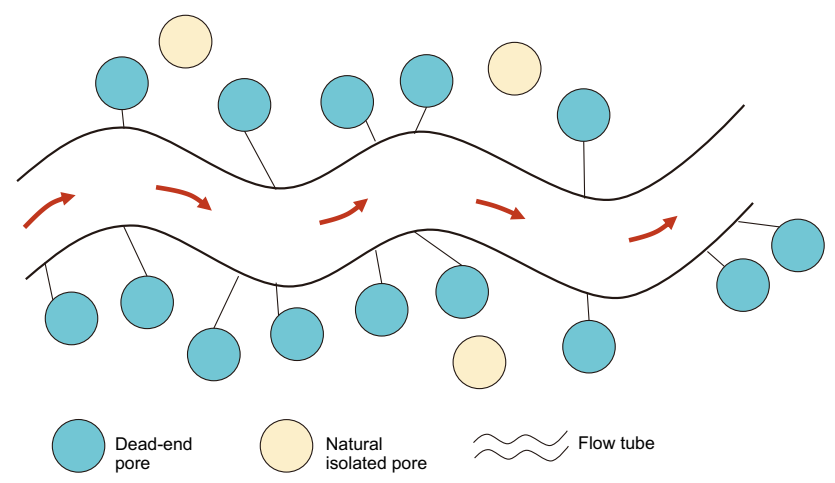

Fig. 1 Capillary model of flow through porous media considering the effects of dead-end pores connected with flow tube in a tight porous medium model is suitable for tight rocks for achieving $S_{\text {wir }}$ accurately under real reservoir conditions.

\section{The new model}

In order to obtain the new irreducible water saturation model for tight sandstone gas reservoirs, the following methods are adopted. First, the fractal scaling theory is modified by considering stress sensitivity in the capillary model. Second, a new capillary model in a tight gas reservoir is established by considering DSW, water film, pressure gradient and temperature. Third, the impacts of stress dependency are integrated into the model to simulate the change of effective stress in the actual tight sandstone gas reservoir.

Figure 2a manifests that the flow paths in the reservoir are composed by a bunch of capillaries with different crosssectional areas, and the size, length and tortuosity satisfy the statistically fractal scaling characteristics. The capillary diameter is equivalent and smooth in the conventional bundle models; however, there are many dead-end pores in the actual porous medium. In order to describe the characteristics of porous media, the small cones are used to describe dead-end pores on the capillary tubes, as shown in Fig. $2 b$. In addition, the mechanism of capillary length variation under different effective stresses has been taken into the new model.

For the simultaneous gas-water flow, as shown in Fig. 2c, there is a gas flow region with a radius of $r_{\mathrm{g}}$, a movable water region with a thickness of $r_{\delta}-r_{\mathrm{g}}$ and an immovable water region including water film and DSW. Generally, there is a critical radius $r_{\mathrm{c}}$ for the capillary bundle which is determined by the capillary pressure. While $r_{\mathrm{s}}>r_{\mathrm{c}}$, the flow pattern is as shown in Fig. 2c. On the contrary $r_{\mathrm{s}} \leq r_{\mathrm{c}}$, the capillary tubes are fully occupied by wetting water. Therefore, there is a critical water saturation under a certain displacement pressure.

In Fig. 2, $L_{0}$ is the representative length of a capillary, $\mathrm{m} ; P_{\mathrm{o}}$ is the overburden pressure, $\mathrm{MPa} ; r_{2}$ is the external radius of a certain pore, $\mathrm{m} ; r_{\mathrm{s}}$ is the inner radius of a certain pore under effective stress, $\mathrm{m} ; r_{\mathrm{g}}$ is the radius of the pores occupied by the gas, $\mathrm{m} ; r_{\delta}$ is the radius of the pores without water film, $\mathrm{m}$.

Assuming the wall of the capillary is hydrophilic, the gas would occupy the center of the tube and the water would stick with the wall. The water in small cones cannot be moved because of losing momentum. The gravity is neglected during the process of gas and water flow in tubes simultaneously (Feng and Serizawa 1999; Israelachvili 2015; Kawahara et al. 2002; Wu et al. 2014), as illustrated in Fig. 2c. The water in sub-capillary pores, dead or stationary water and water film constitute the irreducible water in porous media. 
(a)
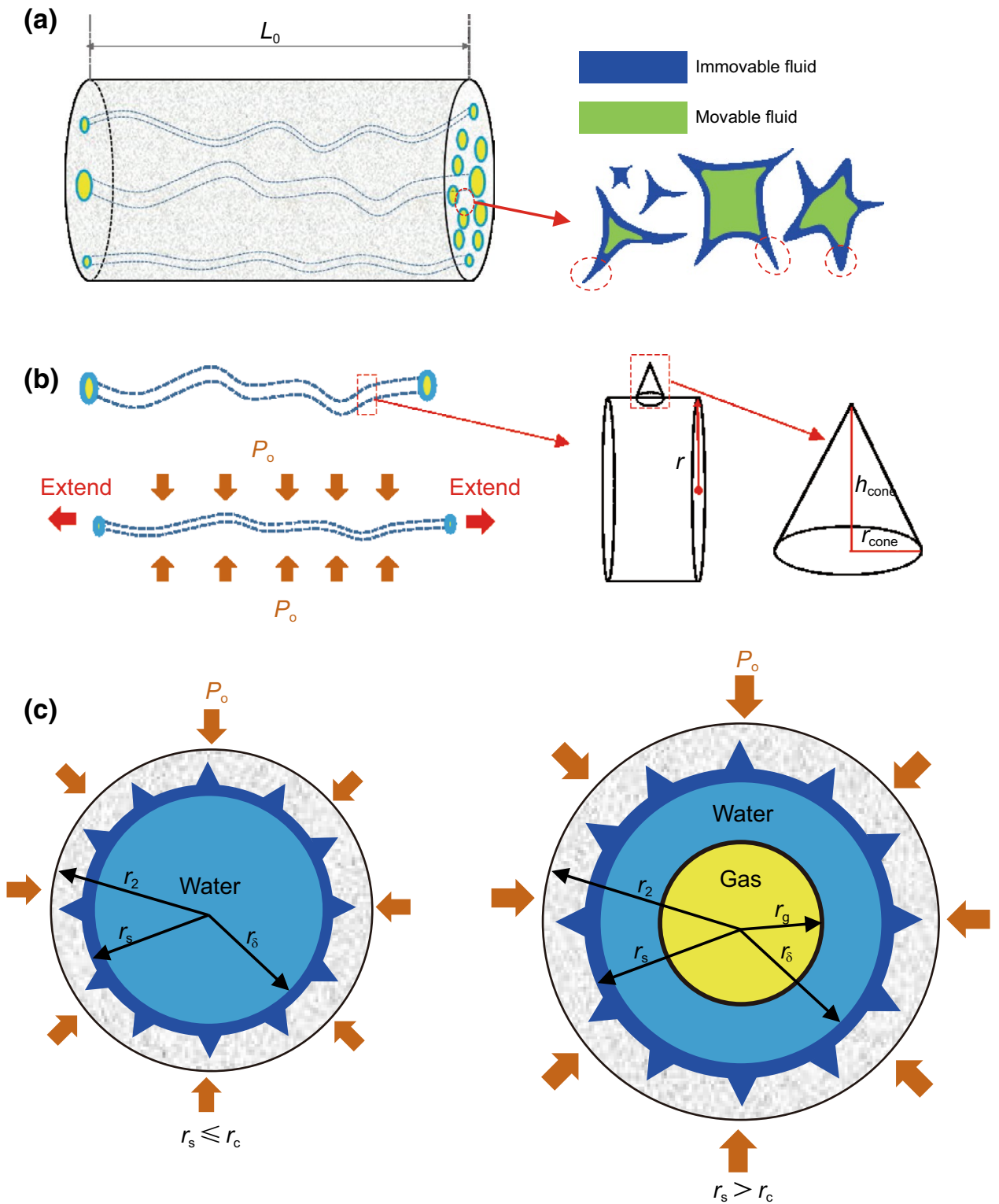

Fig. 2 The new capillary model. a Non-equivalent diameter capillary model. b Capillary model when considering the dead or stationary water and effective stress. $\mathbf{c}$ Gas-water distribution along the circular tube of two-phase flow

The first part of the immobile water is the water trapped in the micro-capillaries because of insufficient displacement force. Ignoring the change of interfacial tension and rock wettability, the critical capillary radius $r_{\mathrm{c}}$ can be obtained as (Cheng et al. 2017):

$r_{\mathrm{c}}=\frac{2 \sigma \cos \theta}{\Delta p}$ where $r_{\mathrm{c}}$ is the critical radius, $\mathrm{m}$; $\sigma$ is the gas-water interfacial tension, $\mathrm{N} / \mathrm{m} ; \Delta p$ is the drawdown pressure, $\mathrm{MPa} ; \theta$ is the wetting angle, degree.

The dead water or stationary water is the second part of the immobile water phase. It is the phenomenon that dead-end pores are filled with water and the water cannot be removed due to flow around effect and complex pore structure (He and Hua 2005; Melrose 1990; Li et al. 2008). In this study, we assumed that multiple small cones are distributed on a single capillary and the volume of total cones and the volume of the capillary have a significantly 
positive correlation. Thus, the relation between them can be expressed as:

$\eta=\frac{V_{\text {cone }}}{V_{\text {tube }}}$

where $V_{\text {cone }}$ is the volume of total cones, $\mathrm{m}^{3} ; V_{\text {tube }}$ is the volume of capillary, $\mathrm{m}^{3}$. We also defined $\eta$ as the DSW coefficient, which is the ratio of the cone volume to the capillary volume. Considering the impact of the volume of cones, the porosity of the capillary model based on the fractal theory needs to be modified. Hence, the relationship between the porosity under real conditions and the porosity in the fractal scaling model is shown as follows:

$\frac{V_{\text {cone }}}{V_{\text {tube }}}=\frac{\phi_{\text {real }}-\phi}{\phi}$

Based on Eq. (2), Eq. (3) will be further modified as:

$\phi_{\text {real }}=\left(1+\frac{V_{\text {cone }}}{V_{\text {tube }}}\right) \phi=(1+\eta) \phi$

where $\phi$ is porosity of the capillary; $\phi_{\text {real }}$ is the real porosity, and it can be tested in the laboratory.

It is noted that the decrease in pore pressure can induce the change of effective stress during the development process of a gas reservoir (David et al. 1994). The radius $r$ of the capillary after deforming can be rewritten as: (Gangi 1978; Lei et al. 2018a)

$r_{\mathrm{s}}=r\left\{1-4\left[\frac{3 \pi\left(1-v^{2}\right) P_{\mathrm{eff}}}{4 E}\right]^{\beta}\right\}$

where $r_{\mathrm{s}}$ is the inner radius of a certain pore under effective stress, $\mathrm{m} ; r$ is the inner radius of a certain pore, $\mathrm{m}$; $P_{\text {eff }}$ is the effective stress, $P_{\text {eff }}=P_{\mathrm{o}}-\alpha p, \mathrm{MPa} ; P_{\mathrm{o}}$ is the overburden pressure, MPa; $p$ is the pore pressure, MPa; $E$ is the rock elastic modulus, $\mathrm{MPa} ; \beta$ is the power law index which is affected by the pore structure, dimensionless; $\alpha$ is the effective stress constant, dimensionless; $\nu$ is Poisson's ratio, dimensionless.

The change of a single capillary in porous media will induce the change of fractal parameters and the calculation of fractal parameter considering stress sensitivity are shown in "Appendixes 1 and 2." The stress may affect the radius and length of the capillary tube and the cone shape on the capillary tube. We assumed that the volume changes of the capillary tube and cones are consistent in porous media. Thus, the DSW coefficient is a constant and it can be expressed as follows:
$\eta=\frac{V_{\text {cone }}^{\prime}}{V_{\text {tube }}^{\prime}}$

where $V_{\text {cone }}^{\prime}$ is the volume of the total cones considering the effective stress, $\mathrm{m}^{3} ; V_{\text {tube }}^{\prime}$ is the volume of the capillary considering the effective stress, $\mathrm{m}^{3}$.

The water film is the third part of the immobile water in the capillaries. It is assumed to adhere to the macropore wall due to the molecular forces making the water molecules bounded on the wall. Previous studies have confirmed that the thickness of the water film is related to the pressure gradient (Mo et al. 2015; Tian et al. 2014, 2015; Yu and Cheng 2002; Yu and Li 2001). Based on the micro-tube experiment, Tian et al. (2014) presented the relationship between the pressure gradient, water viscosity and the thickness of the water film as:

$\delta=\left\{\begin{array}{l}r \cdot 0.25763 \mathrm{e}^{-0.261 r}(\nabla p)^{-0.419} \mu_{\mathrm{w}} \quad(\nabla p<1 \mathrm{MPa} / \mathrm{m}) \\ r \cdot 0.25763 \mathrm{e}^{-0.261 r} \mu_{\mathrm{w}}(\nabla p>1 \mathrm{MPa} / \mathrm{m})\end{array}\right.$

where $\delta$ is the thickness of the water film, $\mu \mathrm{m} ; \nabla p=\Delta p / L_{0}$ is the pressure gradient, $\mathrm{MPa} / \mathrm{m}$; and $\mu_{\mathrm{w}}$ is the water viscosity, $\mathrm{mPa}$ s. The water viscosity is mainly affected by the temperature, and it can be expressed as (Cheng et al. 2017; Li 2006):

$\mu_{\mathrm{w}}=1.4 \mathrm{e}^{-0.0176 T}$

where $T$ is the formation temperature, ${ }^{\circ} \mathrm{C}$.

Based on the above assumption of the gas-water distribution patterns, the volume of the immobile water and the total pores are defined as:

$$
\begin{aligned}
V_{\text {wir }}= & N \int_{r_{\text {mins }}}^{r_{\mathrm{cs}}} \pi r_{\mathrm{s}}^{2} L_{\mathrm{s}}\left(r_{\mathrm{s}}\right) f_{\mathrm{s}}\left(r_{\mathrm{s}}\right) \mathrm{d} r \\
& +N \int_{r_{\mathrm{cs}}}^{r_{\text {maxs }}} \pi\left[r_{\mathrm{s}}^{2}-\left(r_{\mathrm{s}}-\delta\right)^{2}\right] L_{\mathrm{s}}\left(r_{\mathrm{s}}\right) f_{\mathrm{s}}\left(r_{\mathrm{s}}\right) \mathrm{d} r \\
& +\eta N \int_{r_{\text {mins }}}^{r_{\text {maxs }}} r_{\mathrm{s}}^{2} L_{\mathrm{s}}\left(r_{\mathrm{s}}\right) f_{\mathrm{s}}\left(r_{\mathrm{s}}\right) \mathrm{d} r \\
V_{\text {total }}= & (1+\eta) N \int_{r_{\text {mins }}}^{r_{\text {maxs }}} r_{\mathrm{s}}^{2} L_{\mathrm{s}}\left(r_{\mathrm{s}}\right) f_{\mathrm{s}}\left(r_{\mathrm{s}}\right) \mathrm{d} r
\end{aligned}
$$

where $V_{\text {wir }}$ is the volume of the immobile water, $\mathrm{m}^{3} ; V_{\text {total }}$ is the volume of the total pores, $\mathrm{m}^{3} ; N$ is the number of pores in a unit cell; $L_{\mathrm{s}}$ is the tortuous flow path under effective stress, $\mathrm{m} ; f_{\mathrm{s}}$ is the probability density function for pore size-distribution under effective stress; $r_{\mathrm{cs}}$ is the critical pore radius under effective stress, $\mathrm{m} ; r_{\operatorname{maxs}}$ is the maximum pore radius under effective stress, $\mathrm{m} ; r_{\text {mins }}$ is the minimum pore radius under effective stress, $\mathrm{m}$; 
By the definition of the irreducible water saturation, we can obtain the irreducible water saturation $S_{\text {wir: }}$ :

$S_{\text {wir }}=\frac{V_{\text {wir }}}{V_{\text {total }}}$

Inserting Eqs. (9) and (10) into Eq. (11) yields: capillary radius was taken as $0.1 \mu \mathrm{m}$. Then, in order to calculate $S_{\text {wir }}$ values of 10 core samples using the new proposed model in this paper, the DSW coefficient was in the range from 0.01 to 0.02 and the other parameters were consistent with the Cheng et al. model. The relationship curve between the mean absolute error and the

$$
\begin{aligned}
S_{\mathrm{wir}}= & \frac{N \int_{r_{\mathrm{mins}}}^{r_{\mathrm{cs}}} \pi r_{\mathrm{s}}^{2} L_{\mathrm{s}}\left(r_{\mathrm{s}}\right) f_{\mathrm{s}}\left(r_{\mathrm{s}}\right) \mathrm{d} r+N \int_{r_{\mathrm{cs}}}^{r_{\text {maxs }}} \pi\left[r_{\mathrm{s}}^{2}-\left(r_{\mathrm{s}}-\delta\right)^{2}\right] L_{\mathrm{s}}\left(r_{\mathrm{s}}\right) f_{\mathrm{s}}\left(r_{\mathrm{s}}\right) \mathrm{d} r}{(1+\eta) N \int_{r_{\text {mins }}}^{r_{\text {maxs }}} \pi r_{\mathrm{s}}^{2} L_{\mathrm{s}}\left(r_{\mathrm{s}}\right) f_{\mathrm{s}}\left(r_{\mathrm{s}}\right) \mathrm{d} r} \\
& +\frac{\eta N \int_{r_{\text {mins }}}^{r_{\text {maxs }}} \pi r_{\mathrm{s}}^{2} L_{\mathrm{s}}\left(r_{\mathrm{s}}\right) f_{\mathrm{s}}\left(r_{\mathrm{s}}\right) \mathrm{d} r}{(1+\eta) N \int_{r_{\text {mins }}}^{r_{\operatorname{maxs}}} \pi r_{\mathrm{s}}^{2} L_{\mathrm{s}}\left(r_{\mathrm{s}}\right) f_{\mathrm{s}}\left(r_{\mathrm{s}}\right) \mathrm{d} r}
\end{aligned}
$$

Based on the "Appendixes 1 and 2," Eq. (12) can be simplified as follows:

$S_{\text {wir }}=\frac{\int_{r_{\text {mins }}}^{r_{\mathrm{cs}}} r_{\mathrm{s}}^{2-\left(D_{\mathrm{T}}^{\prime}+D_{\mathrm{f}}^{\prime}\right)} \mathrm{d} r+\int_{r_{\mathrm{cs}}}^{r_{\operatorname{maxs}}}\left[r_{\mathrm{s}}^{2}-\left(r_{\mathrm{s}}-\delta\right)^{2}\right] r^{-\left(D_{\mathrm{T}}^{\prime}+D_{\mathrm{f}}^{\prime}\right)} \mathrm{d} r}{(1+\eta) \int_{r_{\text {mins }}}^{r_{\operatorname{maxs}}} r_{\mathrm{s}}^{2-\left(D_{\mathrm{T}}^{\prime}+D_{\mathrm{f}}^{\prime}\right)} \mathrm{d} r}+\frac{\eta}{1+\eta}$

where $D_{\mathrm{f}}{ }^{\prime}$ is the stress-dependent fractal dimension, $D_{\mathrm{T}}{ }^{\prime}$ is the stress-dependent fractal dimension for tortuosity.

\section{Model validation}

A total of 10 low permeability sandstone samples were selected from the Xujiahe Formation in the central Sichuan Basin, and the basic parameters of the wax-sealed core samples (Cheng et al. 2017) are shown in Table 1.

First, the $S_{\text {wir }}$ values of core samples were calculated from the Cheng et al. model under reservoir conditions in which the formation temperature was determined by geothermal gradient formula (Xu et al. 2011) and the critical
DSW coefficient is shown in Fig. 3. It was obvious that the mean absolute error was smallest with $\eta=0.0135$. Finally, the values of $S_{\text {wir }}$ calculated by these two models are contrasted with the measured vales of wax-sealed core samples, and the detailed parameters are presented in Table 2. The comparison results show that the absolute error of $S_{\text {wir }}$ calculated by the Cheng et al. model ranges from $0.033 \%$ to $2.761 \%$ and the absolute error of $S_{\text {wir }}$ calculated by the new model is in the range from $0.006 \%$ to $2.213 \%$ as shown in Table 2 . The $S_{\text {wir }}$ obtained by the proposed model is obviously closer to the measured values of the wax-sealed core samples, which is shown in Fig. 4. It is obvious that the predicted results through this proposed model are more accurate comparing with the Cheng et al. model by considering the influence of DSW coefficient on the $S_{\text {wir }}$.

The application of the new model requires matching experimental data. The DSW coefficient was obtained by fitting the experimental results and was applied to calculate $S_{\text {wir }}$ values of other cores in the next work. A total of 30 low-permeability tight sandstone cores were selected

\begin{tabular}{|c|c|c|c|c|c|c|c|}
\hline Well & Sample No. & Diameter, cm & Length, $\mathrm{cm}$ & Porosity, $\%$ & $\begin{array}{l}\text { Permeability, } \\
\mathrm{mD}\end{array}$ & $\begin{array}{l}\text { Reservoir tempera- } \\
\text { ture, }{ }^{\circ} \mathrm{C}\end{array}$ & $\begin{array}{l}\text { Water } \\
\text { viscosity, } \\
\mathrm{mPa} \mathrm{s}\end{array}$ \\
\hline A & A1 & 2.532 & 3.642 & 5.59 & 0.03 & 68.57 & 0.419 \\
\hline A & $\mathrm{A} 2$ & 2.535 & 4.053 & 13.11 & 2.56 & 68.83 & 0.417 \\
\hline A & A3 & 2.539 & 4.401 & 12.60 & 0.54 & 69.01 & 0.416 \\
\hline A & A4 & 2.528 & 2.282 & 14.09 & 6.48 & 69.25 & 0.414 \\
\hline B & B1 & 2.537 & 4.081 & 6.04 & 0.03 & 75.43 & 0.371 \\
\hline B & B2 & 2.533 & 4.126 & 12.20 & 0.13 & 77.23 & 0.36 \\
\hline $\mathrm{C}$ & $\mathrm{C} 1$ & 2.545 & 4.722 & 13.66 & 0.68 & 84.68 & 0.315 \\
\hline $\mathrm{C}$ & $\mathrm{C} 2$ & 2.546 & 4.807 & 14.51 & 2.25 & 84.66 & 0.316 \\
\hline $\mathrm{C}$ & $\mathrm{C} 3$ & 2.547 & 4.895 & 15.92 & 6.94 & 84.30 & 0.318 \\
\hline $\mathrm{C}$ & $\mathrm{C} 4$ & 2.548 & 4.532 & 12.76 & 1.40 & 83.65 & 0.321 \\
\hline
\end{tabular}

Table 1 Parameters of sandstone core samples used in the experiments (Cheng et al. 2017) 


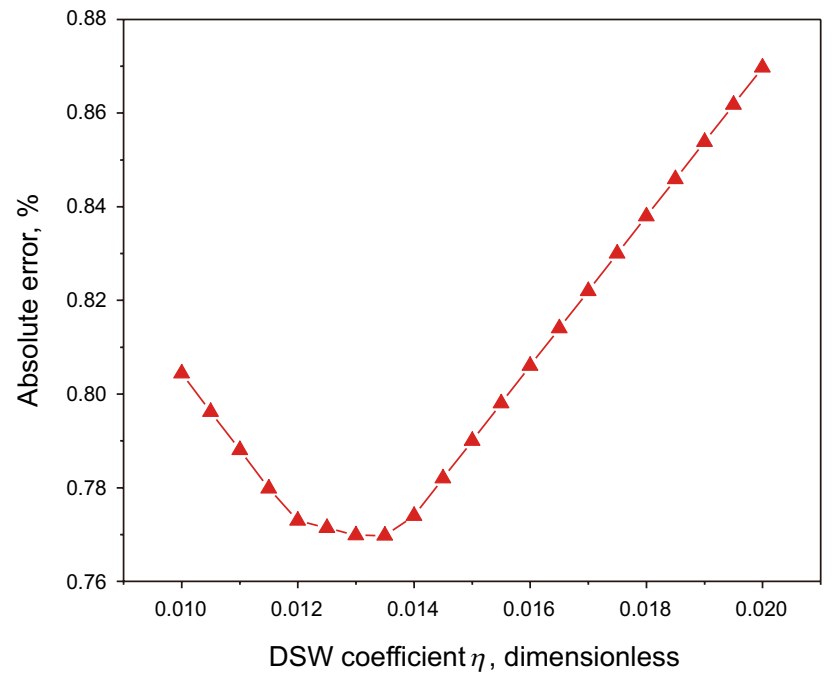

Fig. 3 The relationship between the absolute error and the DSW coefficient

from the Sulige Formation in the Ordos Basin. All cores were randomly divided into groups A and B. Each group (group A and group B) includes fifteen pieces of cores and the basic data of these cores are listed in Tables 3 and 4 . The irreducible water saturation tests were conducted on all cores using the continuous gas drive method at normal temperature and low pressure (2.07 $\mathrm{MPa})$. The experimental apparatus is composed of a pressure control system, a core holding system and a measurement system, as shown in Fig. 5. The injection fluids are synthesized formation water (Table 5) and nitrogen. The synthesized formation water was prepared based on actual composition of the formation water from Sulige Formation in the Ordos Basin. The experimental

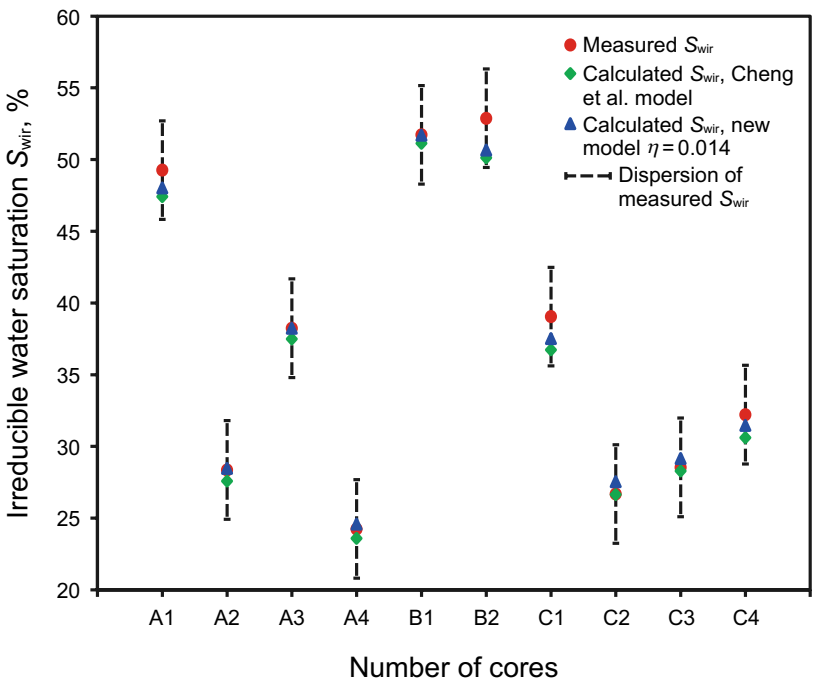

Fig. 4 The irreducible water saturation calculated by different methods

results of irreducible water saturation obtained the gas drive experiments are listed in Tables 3 and 4 . The new model was fitted with the experimental data of group A by adjusting the DSW coefficient. The calculated DSW coefficient is shown in Table 3 and the average value of the DSW coefficient was 0.056 . The values of $S_{\text {wir }}$ calculated from the new model were contrasted with the experimental data, and the detailed parameters are presented in Table 4. From Fig. 6, we can see that the values of $S_{\text {wir }}$ predicted by the proposed model are in a good agreement with the experimental values. Thus, we can conclude that the $S_{\text {wir }}$ can be predicted by the new model more accurately and the DSW coefficient can be determined from the above workflow.

Table 2 Comparison of the irreducible water saturation obtained from the new model and Cheng et al. model with the measured values of 10 wax-sealed core samples $\left(r_{\mathrm{c}}=0.1 \mu \mathrm{m}, \Delta P=7.35 \mathrm{MPa}\right)$

\begin{tabular}{|c|c|c|c|c|c|c|c|c|}
\hline \multirow[t]{2}{*}{ Sample no. } & \multirow[t]{2}{*}{$r_{\max }, \mu \mathrm{m}$} & \multirow[t]{2}{*}{$r_{\min }, \mu \mathrm{m}$} & \multirow[t]{2}{*}{$r_{\text {ave }}, \mu \mathrm{m}$} & \multicolumn{2}{|c|}{ Calculated $S_{\text {wir }}, \%$} & \multirow{2}{*}{$\begin{array}{l}\text { Measured } S_{\text {wir }} \text { of the } \\
\text { wax-sealed core, } \%\end{array}$} & \multicolumn{2}{|c|}{ Absolute error, $\%$} \\
\hline & & & & $\begin{array}{l}\text { Cheng et al. } \\
\text { model }\end{array}$ & $\begin{array}{l}\text { New model } \\
\eta=0.0135\end{array}$ & & $\begin{array}{l}\text { Cheng et al. } \\
\text { model }\end{array}$ & New model \\
\hline A1 & 0.407 & 0.006 & 0.080 & 47.42 & 48.02 & 49.265 & 1.845 & 1.241 \\
\hline $\mathrm{A} 2$ & 2.623 & 0.016 & 0.457 & 27.58 & 28.47 & 28.361 & 0.781 & 0.104 \\
\hline $\mathrm{A} 3$ & 1.019 & 0.010 & 0.176 & 37.49 & 38.25 & 38.241 & 0.751 & 0.006 \\
\hline A4 & 9.947 & 0.016 & 1.087 & 23.59 & 24.58 & 24.245 & 0.655 & 0.337 \\
\hline B1 & 0.407 & 0.004 & 0.059 & 51.14 & 51.70 & 51.723 & 0.583 & 0.022 \\
\hline B2 & 0.630 & 0.004 & 0.121 & 50.12 & 50.67 & 52.881 & 2.761 & 2.213 \\
\hline $\mathrm{C} 1$ & 1.015 & 0.010 & 0.190 & 36.74 & 37.52 & 39.051 & 2.311 & 1.531 \\
\hline $\mathrm{C} 2$ & 2.598 & 0.016 & 0.431 & 26.65 & 27.55 & 26.683 & 0.033 & 0.863 \\
\hline $\mathrm{C} 3$ & 6.136 & 0.010 & 0.853 & 28.29 & 29.16 & 28.542 & 0.252 & 0.622 \\
\hline $\mathrm{C} 4$ & 2.609 & 0.010 & 0.353 & 30.61 & 31.46 & 32.217 & 1.607 & 0.753 \\
\hline Average & & & & & & & 1.158 & 0.769 \\
\hline
\end{tabular}

$r_{\text {ave }}, r_{\max }$ and $r_{\min }$ are the average, maximum and minimum pore radii, respectively, $\mathrm{m} . \Delta P$ is the maximum displacement pressure, MPa 
Table 3 Parameters of sandstone core samples in group A and fitting results of DSW coefficient based on experimental data $\left(r_{\mathrm{c}}=0.1 \mu \mathrm{m}\right.$, $\Delta P=2.07 \mathrm{MPa})$

\begin{tabular}{|c|c|c|c|c|c|c|c|c|c|}
\hline Sample & Diameter, $\mathrm{cm}$ & Length, $\mathrm{cm}$ & Porosity, \% & Permeability, mD & $r_{\max }, \mu \mathrm{m}$ & $r_{\min }, \mu \mathrm{m}$ & $r_{\text {ave }}, \mu \mathrm{m}$ & Measured $S_{\text {wir }}, \%$ & $\begin{array}{l}\text { DSW } \\
\text { coefficient } \\
\eta\end{array}$ \\
\hline A-01 & 2.54 & 4.90 & 6.98 & 0.227 & 34.153 & 0.001 & 0.180 & 57.77 & 0.070 \\
\hline A- 02 & 2.54 & 4.82 & 1.15 & 0.013 & 28.904 & 0.001 & 0.070 & 56.24 & 0.070 \\
\hline A-03 & 2.54 & 4.93 & 3.03 & 0.017 & 31.284 & 0.001 & 0.036 & 57.18 & 0.061 \\
\hline A-04 & 2.54 & 4.49 & 4.85 & 0.121 & 10.331 & 0.001 & 0.282 & 64.86 & 0.059 \\
\hline A- -05 & 2.54 & 4.82 & 5.02 & 0.125 & 9.545 & 0.001 & 0.260 & 65.65 & 0.056 \\
\hline A-06 & 2.54 & 4.95 & 7.24 & 0.600 & 3.997 & 0.001 & 0.705 & 72.73 & 0.054 \\
\hline A-07 & 2.54 & 4.02 & 1.74 & 0.124 & 22.795 & 0.001 & 0.072 & 58.88 & 0.043 \\
\hline A- 08 & 2.54 & 5.24 & 5.59 & 0.234 & 14.178 & 0.001 & 0.177 & 63.47 & 0.051 \\
\hline A-09 & 2.53 & 5.35 & 5.30 & 0.225 & 14.178 & 0.001 & 0.155 & 63.37 & 0.051 \\
\hline A-10 & 2.53 & 5.37 & 4.66 & 0.149 & 24.213 & 0.001 & 0.065 & 60.41 & 0.043 \\
\hline A-11 & 2.53 & 5.28 & 5.00 & 0.162 & 18.188 & 0.001 & 0.064 & 61.17 & 0.061 \\
\hline A-12 & 2.53 & 5.47 & 3.24 & 0.096 & 28.904 & 0.001 & 0.059 & 58.24 & 0.052 \\
\hline A-13 & 2.54 & 5.24 & 3.33 & 0.125 & 31.284 & 0.001 & 0.053 & 58.51 & 0.040 \\
\hline A-14 & 2.53 & 5.23 & 2.19 & 0.121 & 29.356 & 0.001 & 0.127 & 56.79 & 0.063 \\
\hline A- 15 & 2.53 & 5.28 & 5.33 & 0.280 & 14.178 & 0.001 & 0.188 & 63.27 & 0.070 \\
\hline Average & 2.54 & 5.03 & 4.31 & 0.175 & 21.033 & 0.001 & 0.166 & 61.24 & 0.056 \\
\hline
\end{tabular}

Table 4 Comparison of the irreducible water saturation obtained from the new model with the measured values of group B samples $\left(r_{\mathrm{c}}=0.1 \mu \mathrm{m}\right.$, $\Delta P=2.07 \mathrm{MPa})$

\begin{tabular}{|c|c|c|c|c|c|c|c|c|c|c|}
\hline \multirow[t]{2}{*}{ Sample } & \multirow[t]{2}{*}{ Diameter, $\mathrm{cm}$} & \multirow[t]{2}{*}{ Length, $\mathrm{cm}$} & \multirow[t]{2}{*}{ Porosity, $\%$} & \multirow[t]{2}{*}{ Permeability, mD } & \multirow[t]{2}{*}{$r_{\text {max }}, \mu \mathrm{m}$} & \multirow[t]{2}{*}{$r_{\min }, \mu \mathrm{m}$} & \multirow[t]{2}{*}{$r_{\text {ave }}, \mu \mathrm{m}$} & \multicolumn{2}{|l|}{$\mathrm{S}_{\mathrm{wri}}, \%$} & \multirow{2}{*}{$\begin{array}{l}\text { Absolute } \\
\text { error, \% }\end{array}$} \\
\hline & & & & & & & & Measured & $\begin{array}{l}\text { Predicted by new } \\
\text { model } \eta=0.056\end{array}$ & \\
\hline B-01 & 2.54 & 4.92 & 5.63 & 0.083 & 54.440 & 0.001 & 0.154 & 56.87 & 55.88 & 0.99 \\
\hline B-02 & 2.54 & 4.99 & 3.04 & 0.153 & 42.934 & 0.001 & 0.141 & 56.85 & 55.87 & 0.98 \\
\hline B-03 & 2.54 & 4.93 & 5.63 & 0.236 & 15.346 & 0.001 & 0.259 & 63.09 & 62.70 & 0.39 \\
\hline B-04 & 2.53 & 4.84 & 3.04 & 0.041 & 18.162 & 0.001 & 0.033 & 59.81 & 60.55 & 0.74 \\
\hline B-05 & 2.54 & 5.18 & 4.09 & 0.485 & 15.330 & 0.001 & 0.438 & 61.24 & 62.14 & 0.90 \\
\hline B-06 & 2.53 & 5.15 & 4.00 & 0.478 & 17.978 & 0.001 & 0.053 & 61.72 & 61.11 & 0.61 \\
\hline B-07 & 2.54 & 5.00 & 1.6 & 0.022 & 14.178 & 0.001 & 0.050 & 61.23 & 60.89 & 0.34 \\
\hline B-08 & 2.53 & 4.87 & 4.98 & 0.132 & 14.178 & 0.001 & 0.046 & 63.73 & 62.98 & 0.75 \\
\hline B-09 & 2.53 & 4.97 & 2.52 & 0.216 & 14.178 & 0.001 & 0.063 & 62.37 & 61.75 & 0.62 \\
\hline B-10 & 2.54 & 4.41 & 3.27 & 0.192 & 14.178 & 0.001 & 0.049 & 62.92 & 62.23 & 0.69 \\
\hline B-11 & 2.54 & 3.57 & 6.55 & 0.300 & 16.610 & 0.001 & 0.098 & 62.42 & 62.48 & 0.06 \\
\hline B-12 & 2.54 & 3.81 & 2.34 & 0.234 & 15.346 & 0.001 & 0.105 & 61.46 & 61.10 & 0.36 \\
\hline B-13 & 2.54 & 3.62 & 4.13 & 0.364 & 27.876 & 0.001 & 0.095 & 58.68 & 58.66 & 0.02 \\
\hline B-14 & 2.54 & 3.63 & 7.72 & 0.768 & 35.615 & 0.001 & 0.092 & 59.51 & 58.51 & 1.00 \\
\hline B-15 & 2.52 & 5.30 & 4.39 & 0.787 & 15.937 & 0.001 & 0.453 & 68.42 & 68.91 & 0.49 \\
\hline Average & 2.54 & 4.61 & 4.20 & 0.299 & 21.486 & 0.00 & 0.142 & 61.35 & 61.05 & 0.60 \\
\hline
\end{tabular}

In order to verify the reliability of the model proposed in this paper, different models were used to calculate the irreducible water saturation and the predicted results are shown in Fig. 7. The Ofagbohunmi et al. model (2012) (Ofagbohunmi et al. 2012) is an empirical relationship between the $S_{\text {wir }}$ and the normalized porosity during compaction. In $\mathrm{Li}$ et al. model ( $\mathrm{Li}$ et al. 2010), the irreducible water saturation simulations were conducted on tight sandstone samples with the initial porosity $(\phi)$ of $6.17 \%$, initial permeability $(K)$ of $0.0951 \times 10^{-3} \mu \mathrm{m}^{2}$ and the initial 


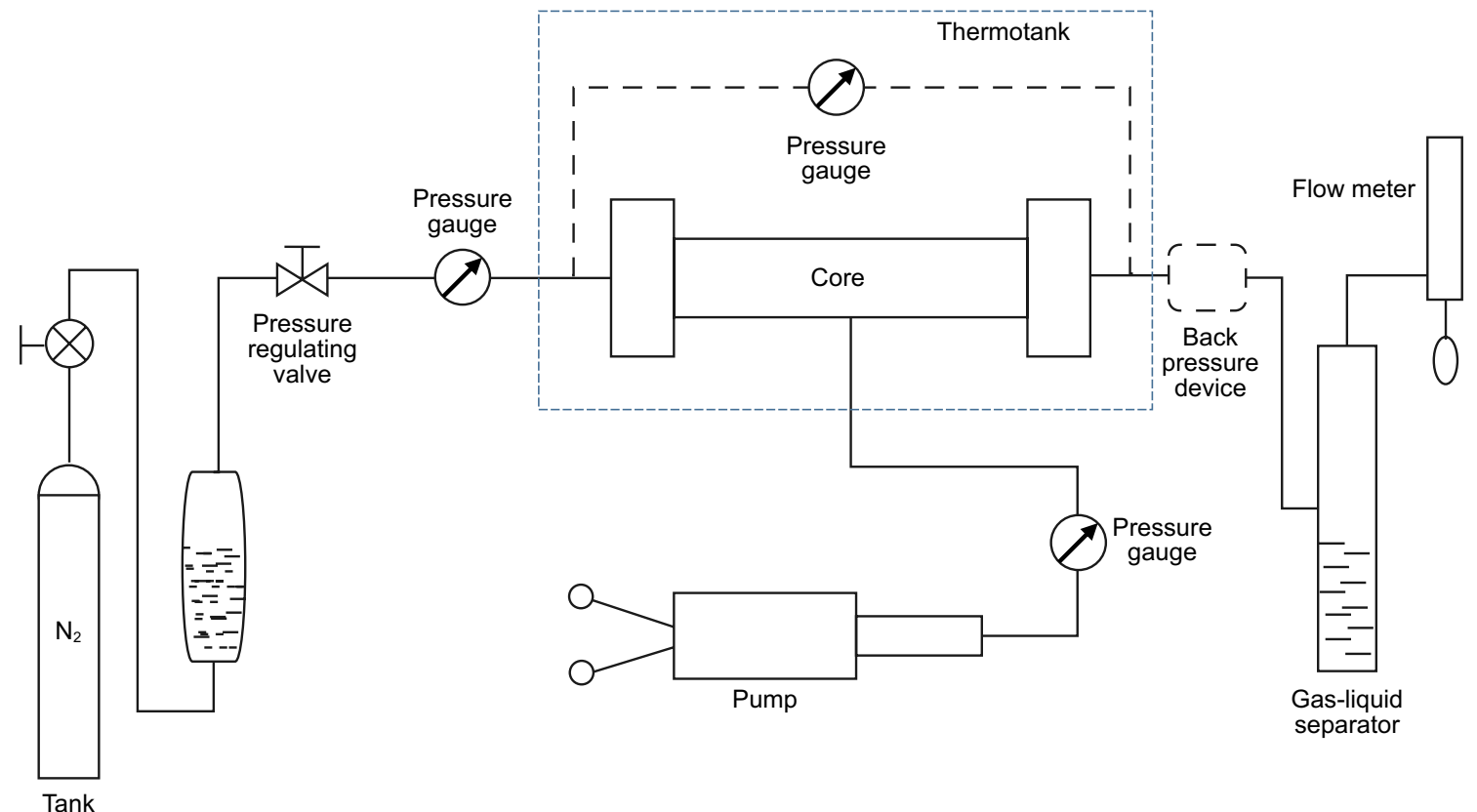

Fig. 5 The flow diagram of the apparatus for irreducible water saturation measurements

Table 5 Conposition of the synthesized formation water

\begin{tabular}{llllllllll}
\hline \multicolumn{2}{l}{ Concentration, $\mathrm{mg} / \mathrm{L}$} & \multicolumn{1}{c}{} & & Salinity, $\mathrm{mg} / \mathrm{L}$ & Water type & $\mathrm{pH}$ & $\mathrm{Density}, \mathrm{g} / \mathrm{m}^{3}$ \\
\hline $\mathrm{K}^{+}+\mathrm{Na}^{+}$ & $\mathrm{Ca}^{2+}$ & $\mathrm{Mg}^{2+}$ & $\mathrm{SO}_{4}^{2-}$ & $\mathrm{HCO}_{3}^{-}$ & $\mathrm{Cl}^{-}$ & & & \\
\hline 2984 & 1601 & 115 & 1556 & 682 & 6487 & 14305 & $\mathrm{CaCl}_{2}$ & 6.2 & 1.013 \\
\hline
\end{tabular}

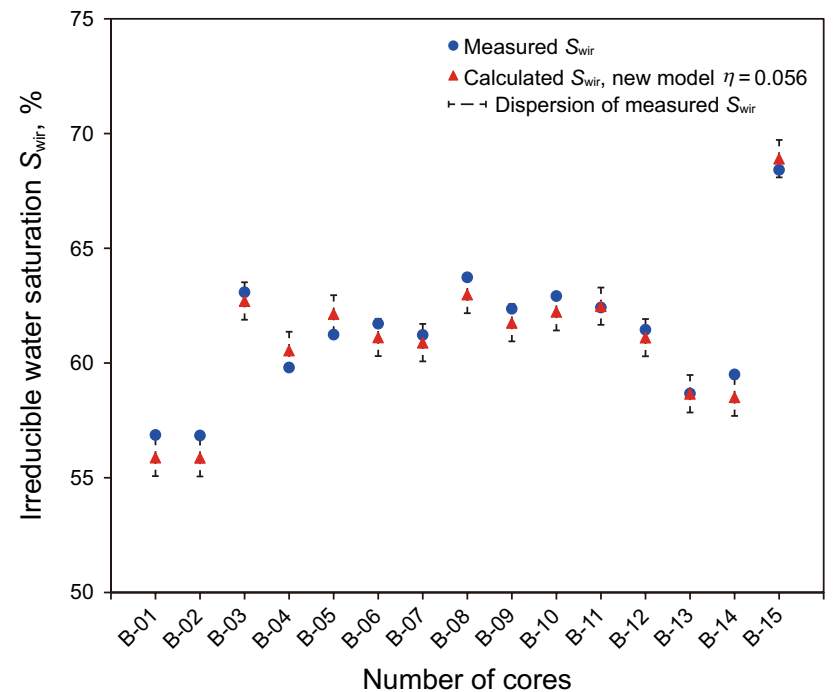

Fig. 6 The irreducible water saturation values obtained from experiments and the new model

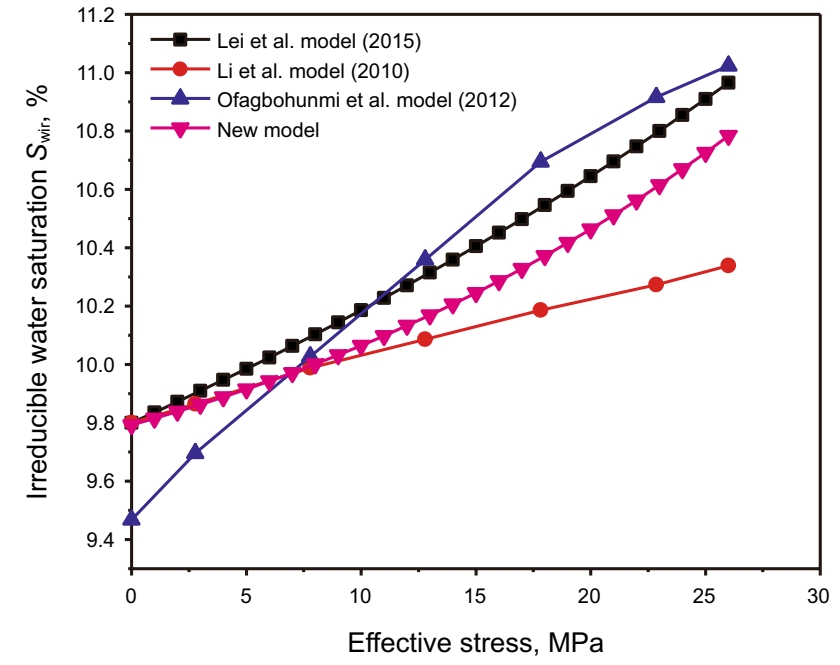

Fig. 7 The comparison between the newly developed model and other models (Lei et al. 2015; Li et al. 2010; Ofagbohunmi et al. 2012) 
Table 6 Description of the relevant parameters in the new model

\begin{tabular}{ll}
\hline Parameters & Values \\
\hline Maximum pore radius $r_{\text {max }}, \mu \mathrm{m}$ & 1.836 \\
Minimum pore radius $r_{\mathrm{min}}, \mu \mathrm{m}$ & 0.016 \\
Permeability $K, \mu \mathrm{m}^{2}$ & $0.0951 \times 10^{-3}$ \\
Initial irreducible water saturation $S_{\mathrm{wc} 0}, \%$ & 9.8 \\
Porosity $\phi, \%$ & 6.17 \\
Rock elastic modulus $E, \mathrm{MPa}$ & $1.05 \times 10^{3}$ \\
Rock Poisson's ratio $v$, dimensionless & 0.25 \\
Temperature $T,{ }^{\circ} \mathrm{C}$ & 80 \\
Maximum displacement pressure $\Delta P, \mathrm{MPa}$ & 4.38 \\
Gas-water interfacial tension $\sigma, \mathrm{mN} / \mathrm{m}$ & 70 \\
DSW coefficient $\eta$, dimensionless & 0 \\
\hline
\end{tabular}

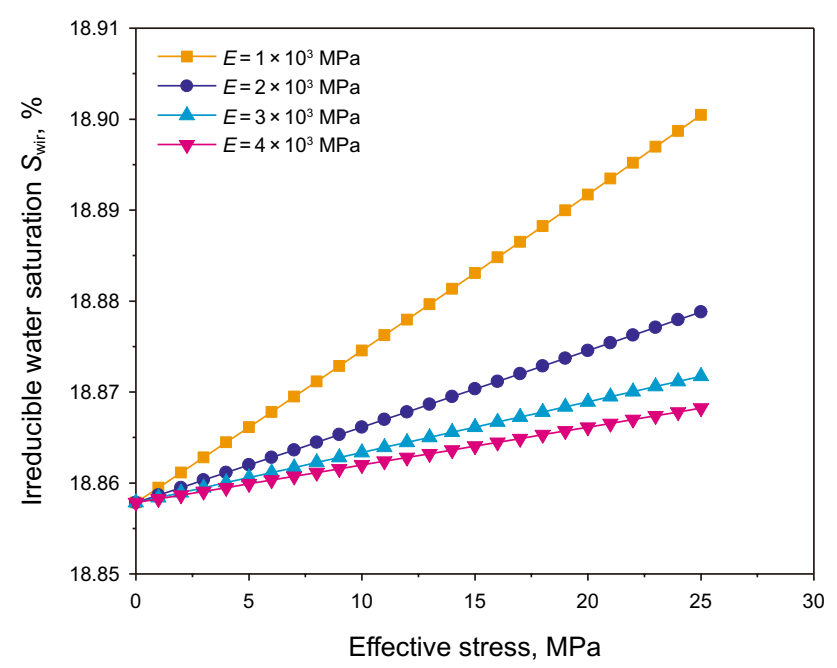

Fig. 8 The irreducible water saturation versus effective stress at different rock elastic moduli

irreducible water saturation of $9.8 \%$. In Lei et al. model (2015) (Lei et al. 2015), the initial porosity $\phi=6.17 \%$, the Euclidean dimension $d=2$, the initial irreducible water saturation $S_{\mathrm{wc} 0}=9.8 \%$, rock Poisson's ratio $\nu=0.25$, and the rock elastic modulus $E=1.05 \times 10^{3} \mathrm{MPa}$. In addition, the initial maximum and minimum radii, $r_{\max }$ and $r_{\text {min }}$, were 1.836 and $0.016 \mu \mathrm{m}$, respectively, which can be consistent with the initial permeability $K=0.0951 \times 10^{-3} \mu \mathrm{m}^{2}$. The calculated results based on Eq. (13) and the relevant parameters applied are listed in Table 6.

It can be observed from Fig. 7 that the $S_{\text {wir }}$ increases with an increase in the effective stress and the new model predictions are in good consistency with other models.

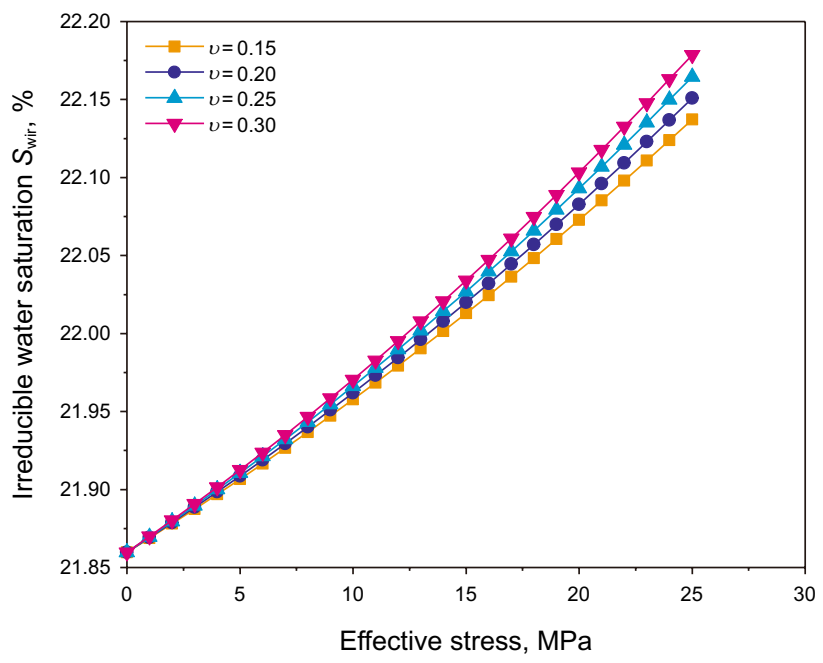

Fig. 9 The irreducible water saturation versus effective stress at different rock Poisson's ratios

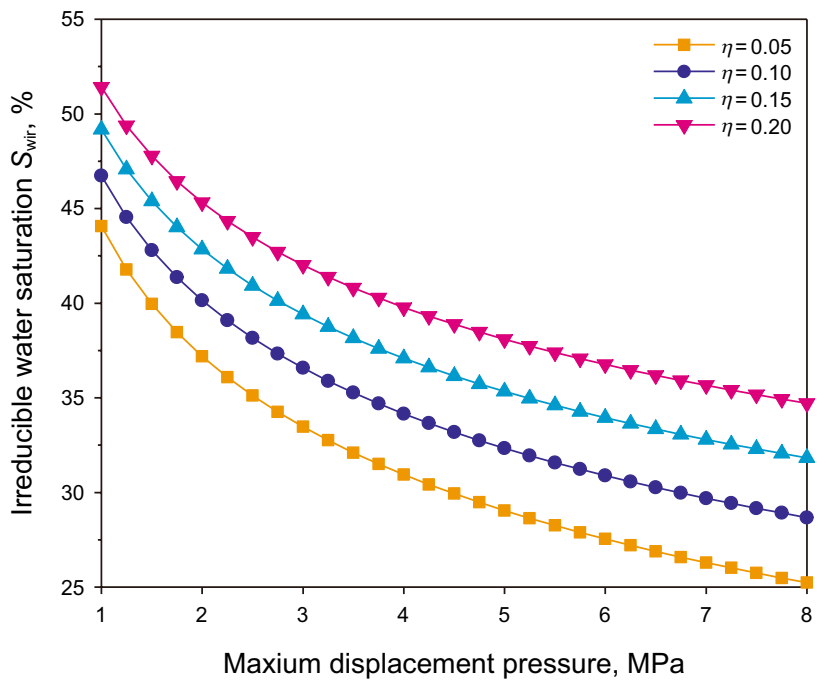

Fig. 10 The irreducible water saturation versus maximum displacement pressure at different DSW coefficients

\section{Results and discussion}

It can be observed from Figs. 8 and 9 that the $S_{\text {wir }}$ increases with an increase in the effective stress and the changing trend is consistent with the result of model validation. The reason is that the pore radius is changed, which is caused by the stress effect. A further explanation is that the increase in the effective stress means the cross-sectional area of capillary bundles decreasing and results in the radius of more capillaries less than the critical capillary radius. It can also be observed from Fig. 8 that the higher $S_{\text {wir }}$ corresponds to the lower rock elastic modulus. 


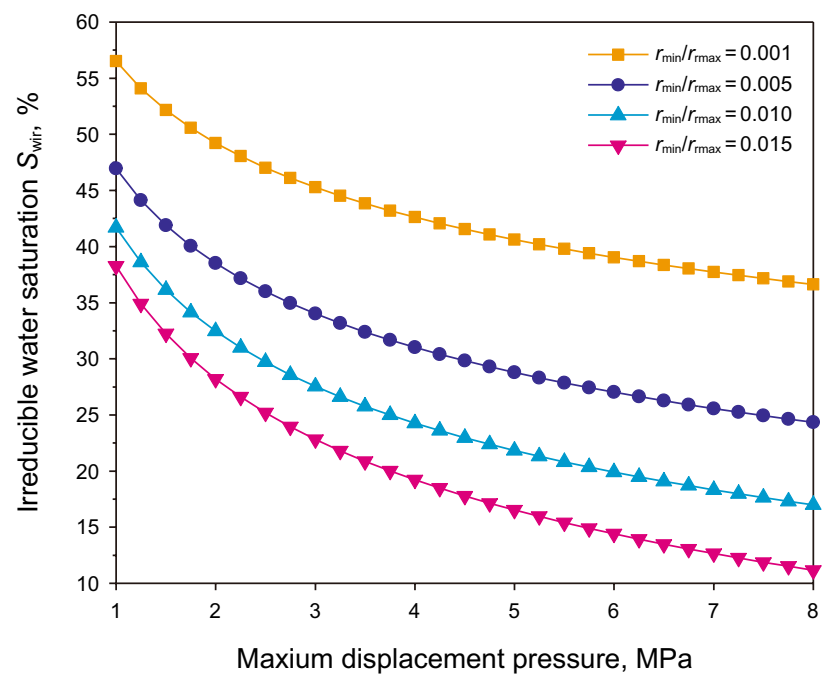

Fig. 11 The irreducible water saturation versus maximum displacement pressure at different ratios $r_{\min } / r_{\max }$

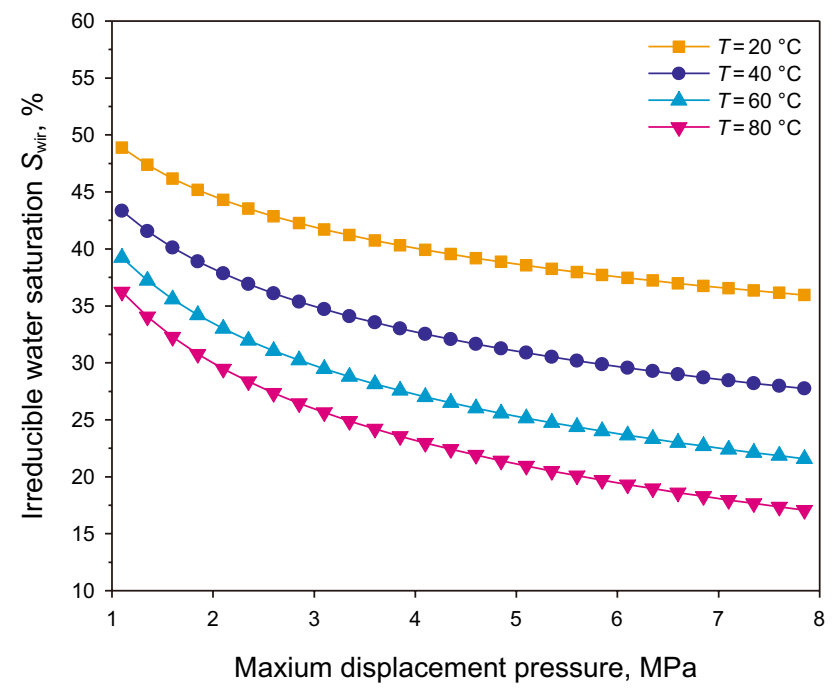

Fig. 12 The irreducible water saturation versus maximum displacement pressure at different temperatures

The reason for this result is that the lower rock elastic modulus is, the lower resistance to contract capillary bundles and the easier changing the rock microscopic pore structure. Figure 9 also demonstrates that the $S_{\text {wir }}$ is higher when Poisson's ratio is higher. The phenomenon can be explained that the higher Poisson's ratio is, the higher elongation of capillary bundles and more pore space contacting with water. However, the changing range of $S_{\text {wir }}$ with Poisson's ratio is not very large. The transverse strain of porous media is very small in actual reservoirs, so the proposed model is in agreement with the actual physical situation.
The increasing extent of the $S_{\text {wir }}$ increases with the increase in the DSW coefficient, as shown in Fig. 10. It can be explained by that the more complicated the structure of porous media, the more dead-end pores are filled with immobile water, which results in the increase of $S_{\text {wir }}$

When the $r_{\max }$ has a constant value of $1.68 \mu \mathrm{m}$, the ratio $r_{\min } / r_{\max }$ is changed. (The result of $S_{\text {wir }}$ shown in Fig. 11.) At a certain maximum displacement pressure, the $S_{\text {wir }}$ increases with the decrease in the ratio $r_{\min } / r_{\text {rmax }}$. The increase in $S_{\text {wir }}$ value indicates that when the $r_{\text {min }}$ becomes smaller, the pore radius decreases, and more immobile water will be adsorbed on the surface of porous media on account of the increase in the specific area of the porous media. In addition, the radius of more capillaries is less than the critical capillary radius with an increase in the ratio $r_{\min } / r_{\max }$. Therefore, the $S_{\text {wir }}$ will be increased.

Figure 12 shows that the $S_{\text {wir }}$ decreases with the increase in the formation temperature if the maximum displacement pressure remains constant. Theoretical analysis shows that different wettabilities may result in different distributions of irreducible water on the rock surface (She and Sleep 1998; Zhang et al. 2016, 2017). As the temperature increases, the water viscosity decreases and the water film thickness becomes thinner. The model proposed in this paper is based on the hydrophilic rock model. Therefore, $S_{\text {wir }}$ decreases with increasing temperature.

\section{Conclusions}

In this paper, a new theoretical model is derived for calculating $S_{\text {wir }}$ in tight gas reservoirs, which is based on the capillary model and fractal theory. This new model takes into account the effects of the DSW, water film, stress and the formation temperature. The accuracy and applicability of this new model for tight sandstone reservoirs are verified by comparing the results of previous studies and experimental data.

The theoretical study of $S_{\text {wir }}$ under reservoir conditions shows that the $S_{\text {wir }}$ is related to the effective stress, rock elastic modulus, pore radius, DSW coefficient, formation temperature and other microstructural parameters. Based on the proposed model, the parametric study shows that the $S_{\text {wir }}$ increases with the increases in the effective stress and Poisson's ratio of rocks and a decrease in the elastic modulus of rocks. For a given maximum displacement pressure in a hydrophilic reservoir, the lower ratio $r_{\text {min }} / r_{\text {rmax }}$, higher DSW coefficient, and lower formation temperature yield higher $S_{\text {wir }}$

The proposed model is developed considering the effects of DSW. However, the method for describing the effect of DSW is still idealized in this paper. The gas-water twophase fluid flow in a tight gas reservoir under the condition 
of effective stress and variable irreducible water saturation is an active and challenging research field. The research field is currently in progress and requires more investigation.

Acknowledgements The research is supported by the National Science Foundation (51904324, 51674279, 51804328), the Major National Science and Technology Project (2017ZX05009-001, 2017ZX05072), the Key Research and Development Program (2018GSF116004), the China Postdoctoral Science Foundation (2019T120616), the Funding for Scientific Research of China University of Petroleum East China (YJ20170013), and Graduate Innovative Engineering project (YCX2019023).

Open Access This article is licensed under a Creative Commons Attribution 4.0 International License, which permits use, sharing, adaptation, distribution and reproduction in any medium or format, as long as you give appropriate credit to the original author(s) and the source, provide a link to the Creative Commons licence, and indicate if changes were made. The images or other third party material in this article are included in the article's Creative Commons licence, unless indicated otherwise in a credit line to the material. If material is not included in the article's Creative Commons licence and your intended use is not permitted by statutory regulation or exceeds the permitted use, you will need to obtain permission directly from the copyright holder. To view a copy of this licence, visit http://creativecommons.org/licenses/by/4.0/.

\section{Appendix 1: Fractal scaling theory}

Previous studies have suggested that natural porous media have the fractal characteristics (Hansen and Skjeltorp 1988; Katz and Thompson 1985; Ozhovan 1993; Yu and Liu 2004); in addition, the microstructures and porous size distribution of porous media undoubtedly have fractal characters (Yu and Cheng 2002; Yu and Li 2001). Based on the fractal scaling theory, the cumulative pore size distribution can be reasonably expressed by the following equation (Majumdar and Bhushan 1990; Xu et al. 2013):

$N(\xi>r)=\left(\frac{r_{\max }}{r}\right)^{D_{\mathrm{f}}}$

where $r$ and $r_{\max }$ are the radius of a certain pore and the maximum pore, respectively; $\xi$ is the length scale; $N$ is the number of pores; $D_{\mathrm{f}}$ is the fractal dimension for pore size distribution.

For tight sandstones, the ratio $r_{\min } / r_{\max }$ in porous media can be obtained through the following equation:

$\int_{r_{\min }}^{r_{\max }} f(r) \mathrm{d} r \approx 1$

which indicates that the tight sandstones truly have fractal characters. Fractal dimension can be determined by porosity $\phi$, and the ratio $r_{\min } / r_{\max }$ in the natural porous media (Yu and $\mathrm{Li} 2001$ ):
$D_{\mathrm{f}}=d-\frac{\ln \phi}{\ln \left(r_{\min } / r_{\max }\right)}$

where $\phi$ is the porosity; $d$ is the Euclidean dimension; $r_{\min }$ is the minimum pore radius. In addition, the number of pores from the minimum size $r_{\text {min }}$ to the maximum size $r_{\max }$ can be determined by the following equation:

$N=\left(\frac{r_{\max }}{r_{\min }}\right)^{D_{\mathrm{f}}}$

Generally, it is no doubt that the pores in the porous media are numerous in Eq. (4). After differentiating Eq. (4), the number of pores from the range $r$ to $r+\mathrm{d} r$ can also be expressed as (Yu and Cheng 2002; Yu and Li 2001):

$-\mathrm{d} N=D_{\mathrm{f}} r_{\max }^{D_{\mathrm{f}}} r^{-\left(D_{\mathrm{f}}+1\right)} \mathrm{d} r$

where $-\mathrm{d} N>0$, which implies that the number of capillary bundles decreases with the increase in the capillary diameter.

Then, the probability density function for pore size distribution can be determined as (Yu and Cheng 2002):

$f(r)=D_{\mathrm{f}} r_{\max }^{D_{\mathrm{f}}} r^{-\left(D_{\mathrm{f}}+1\right)}$

where $f(r)$ is the probability density function for pore size-distribution in the rock.

Due to the tortuous nature of those capillaries, the actual length of that $L>L_{0}$, in which $L_{0}$ is the representative length of a capillary (Xu et al. 2013). The length $L(r)$ of a tortuous flow path is related to the capillary radius and the capillary length based on the self-similar fractal law (Bonnet et al. 2001):

$L(r)=(2 r)^{1-D_{\mathrm{T}}} L_{0}^{D_{\mathrm{T}}}$

where $D_{\mathrm{T}}$ is the tortuosity fractal dimension; $L(r)$ is the tortuous flow path, $\mathrm{m}$; $L$ is the actual length of the capillary; and $L_{0}$ is the representative length of these capillary. The fractal dimension for tortuosity $D_{\mathrm{T}}$ can be determined as follows (Yu 2005; Lei et al. 2015; Xu and Yu 2008; Zheng et al. 2013):

$D_{\mathrm{T}}=1+\frac{\ln \tau_{\mathrm{ave}}}{\ln \left(L_{0} / 2 r_{\mathrm{ave}}\right)}$

where the average tortuosity is given by:

$\tau_{\text {ave }}=\frac{1}{2}\left[1+\frac{1}{2} \sqrt{1-\phi}+\sqrt{1-\phi} \frac{\sqrt{\left(\frac{1}{\sqrt{1-\phi}}-1\right)^{2}+\frac{1}{4}}}{1-\sqrt{1-\phi}}\right]$ 
$\frac{L_{0}}{2 r_{\mathrm{ave}}}=\frac{D_{\mathrm{f}}-1}{\sqrt{D_{\mathrm{f}}}}\left[\frac{1-\phi}{\phi} \frac{\pi}{4\left(2-D_{\mathrm{f}}\right)}\right]^{1 / 2} \frac{r_{\text {max }}}{r_{\min }}$

where $\tau_{\text {ave }}$ is the average tortuosity; $r_{\text {ave }}$ is the average pore radius.

The total pore area on the cross section of the porous media, as suggested by Xu et al. (2013), can be obtained as:

$A=\frac{\pi D_{\mathrm{f}}(1-\phi) r_{\max }^{2}}{\phi\left(2-D_{\mathrm{f}}\right)}$

The representative length $L_{0}$ can be written as (Yu and Cheng 2002):

$L_{0}=\sqrt{A}=r_{\max } \sqrt{\frac{\pi D_{\mathrm{f}}(1-\phi)}{\phi\left(2-D_{\mathrm{f}}\right)}}$

where $A$ is the cross-sectional area of the sample, $\mathrm{m}^{2}$.

\section{Appendix 2: Fractal porous media considering stress sensitivity}

During the gas production of actual tight sandstone reservoirs, the decrease in pore pressure during production would induce significant modifications of the stress field, resulting in an increase in the effective stress applied on the reservoirs. (Archer 2008; Gangi 1978; Lei et al. 2018b; McKee et al. 1988; McKinney et al. 2002; Tan et al. 2015; Zhu 2013). The increased effective stress corresponds to the compaction of rock, which will reduce the radius of the pores and decrease the porosity of porous media.

The deformed capillary radius can be rewritten as (Gangi 1976, 1978; Lei et al. 2018a):

$r_{\mathrm{s}}=r\left\{1-4\left[\frac{3 \pi\left(1-v^{2}\right) P_{\mathrm{eff}}}{4 E}\right]^{\beta}\right\}$

where $E$ is the rock elastic modulus, MPa; $\nu$ is Poisson's ratio, dimensionless; $\beta$ is the power law index which is affected by the pore structure; and $P_{\text {eff }}$ is the effective stress, MPa.

Assuming the total number of pores is constant under different stress conditions, then the following equation can be express as (Lei et al. 2015, 2018b):

$N=\left(\frac{r_{\max }}{r_{\min }}\right)^{D_{\mathrm{f}}}=\left(\frac{r_{\operatorname{maxs}}}{r_{\text {mins }}}\right)^{D_{\mathrm{f}}^{\prime}}$ where $D_{\mathrm{f}}$ 'is the stress-dependent fractal dimension, dimensionless, and it can be rewritten as:

$D_{\mathrm{f}}^{\prime}=D_{\mathrm{f}} \frac{\ln \left(r_{\max } / r_{\min }\right)}{\ln \left(r_{\text {maxs }} / r_{\text {mins }}\right)}$

The expression of rock porosity after deformation can be written as:

$\phi_{\mathrm{s}}=\left(r_{\max } / r_{\min }\right)^{d-D_{\mathrm{f}}^{\prime}}$

The stress-dependent tortuosity fractal dimension can be express as:

$D_{\mathrm{T}}^{\prime}=1+\frac{\ln \tau_{\text {aves }}}{\ln \left(L_{0}^{\prime} / 2 r_{\text {aves }}\right)}$

where

$\tau_{\mathrm{aves}}=\frac{1}{2}\left[1+\frac{1}{2} \sqrt{1-\phi_{\mathrm{s}}}+\sqrt{1-\phi_{\mathrm{s}}} \frac{\sqrt{\left(\frac{1}{\sqrt{1-\phi_{\mathrm{s}}}}-1\right)^{2}+\frac{1}{4}}}{1-\sqrt{1-\phi_{\mathrm{s}}}}\right]$

$\frac{L_{0}^{\prime}}{2 r_{\text {aves }}}=\frac{D_{\mathrm{f}}^{\prime}-1}{\sqrt{D_{\mathrm{f}}^{\prime}}}\left[\frac{1-\phi_{\mathrm{s}}}{\phi_{\mathrm{s}}} \frac{\pi}{4\left(2-D_{\mathrm{f}}^{\prime}\right)}\right]^{1 / 2} \frac{r_{\text {maxs }}}{r_{\text {mins }}}$

$L_{0}^{\prime}=r_{\operatorname{maxs}} \sqrt{\frac{\pi D_{\mathrm{f}}^{\prime}\left(1-\phi_{\mathrm{s}}\right)}{\phi_{\mathrm{s}}\left(2-D_{\mathrm{f}}^{\prime}\right)}}$

where $\tau_{\text {aves }}$ is the average tortuosity under effective stress; $r_{\text {aves }}$ is the pore radius under effective stress, $\mathrm{m} ; L_{0}{ }^{\prime}$ is the representative length of a capillary under effective stress, $m$.

The length of porous media under effective stress conditions can be expressed as (Hibbeler 1997; Tan et al. 2015):

$L_{\mathrm{s}}\left(r_{\mathrm{s}}\right)=\left(1-\frac{P_{\text {eff }}}{\nu E}\right)\left(\frac{r}{F}\right)^{1-D_{\mathrm{T}}^{\prime}} L_{0}^{D_{\mathrm{T}}^{\prime}}$

where $F$ is the shape factor, dimensionless.

\section{References}

Archer RA. Impact of stress sensitive permeability on production data analysis. In: SPE unconventional reservoirs conference. Society of Petroleum Engineers. 2008. https://doi.org/10.2118/114166-MS.

Bear J, Rubinstein B, Fel L. Capillary pressure curve for liquid menisci in a cubic assembly of spherical particles below irreducible saturation. Transp Porous Med. 2011;89(1):63-73. https://doi. org/10.1007/s11242-011-9752-7. 
Bonnet E, Bour O, Odling NE, et al. Scaling of fracture systems in geological media. Rev Geophys. 2001;39(3):347-83. https://doi. org/10.1029/1999RG000074.

Borgia G, Bortolotti V, Brancolini A, Brown R, Fantazzini P. Developments in core analysis by NMR measurements. Magn Reson Imaging. 1996;14(7-8):751-60. https://doi.org/10.1016/S0730 -725X(96)00160-9.

Cheng Y, Zhang C, Zhu L. A fractal irreducible water saturation model for capillary tubes and its application in tight gas reservoir. J Pet Sci Eng. 2017;159:731-9. https://doi.org/10.1016/j. petrol.2017.09.079.

Civan F. Scale effect on porosity and permeability: kinetics, model, and correlation. AIChE J. 2001;47(2):271-87. https://doi.org/10.1002/ aic.690470206.

Coskun SB, Wardlaw NC. Influences of pore geometry, porosity and permeability on initial water saturation-An empirical method for estimating initial water saturation by image analysis. J Pet Sci Eng. 1995;12(4):295-308. https://doi.org/10.1016/09204105(94)00051-5.

David C, Wong T-F, Zhu W, Zhang J. Laboratory measurement of compaction-induced permeability change in porous rocks: implications for the generation and maintenance of pore pressure excess in the crust. Pure Appl Geophys. 1994;143(1-3):425-56. https:// doi.org/10.1007/BF00874337.

Feng Z, Serizawa A. Visualization of two-phase flow patterns in an ultra-small tube. In: Proceedings of the 18th multiphase flow symposium of Japan, Osaka, Japan; 1999. p. 33-36.

Gangi AF. Hertz theory applied to the porosity-pressure, permeabilitypressure and failure strength-porosity variations of porous rocks. In: The 17th US symposium on rock mechanics (USRMS). American Rock Mechanics Association, 1976.

Gangi AF. Variation of whole and fractured porous rock permeability with confining pressure. Int J Rock Mech Min Sci Geomech Abstr. 1978;15(5):249-57. https://doi.org/10.1016/0148-9062(78)90957 $-9$.

Goral J, Deo M, Andrew M. Pore network modeling of Marcellus Shale using digital rock analysis with machine learning image segmentation. ZEISS Application Note; 2018.

Hansen JP, Skjeltorp AT. Fractal pore space and rock permeability implications. Phys Rev B. 1988;38(4):2635. https://doi. org/10.1103/PhysRevB.38.2635.

$\mathrm{He}$ CZ, Hua MQ. Characteristics of pore structure and physical property of low permeability sandstone reservoir. Xinjiang Pet Geol. 2005;26(3):280-4 (in Chinese).

Hibbeler RC. Mechanics of materials. Upper Saddle River: Prentice Hall International; 1997.

Israelachvili J. Intermolecular and surface forces. Cambridge: Academic Press; 2015.

Katz AJ, Thompson AH. Fractal sandstone pores: implications for conductivity and pore formation. Phys Rev Lett. 1985;54(12):1325-8. https://doi.org/10.1103/PhysRevLett.54.1325.

Kawahara A, Chung PMY, Kawaji M. Investigation of two-phase flow pattern, void fraction and pressure drop in a microchannel. Int $\mathrm{J}$ Multiphase Flow. 2002;28(9):1411-35. https://doi.org/10.1016/ S0301-9322(02)00037-X.

Lei G, Dong P, Wu Z, et al. A fractal model for the stress-dependent permeability and relative permeability in tight sandstones. J Can Pet Technol. 2015;54(1):36-48. https://doi.org/10.2118/17389 7-PA.

Lei G, Dong Z, Li W, Wen Q, Wang C. Theoretical study on stress sensitivity of fractal porous media with irreducible water. Fractals. 2018a;26(1):1850004. https://doi.org/10.1142/S0218348X1 8500044

Lei G, Mo S, Dong Z, Wang CAI, Li W. Theoretical and experimental study on stress-dependency of oil-water relative permeability in fractal porous media. Fractals. 2018b;26(2):1840010. https://doi. org/10.1142/S0218348X18400108.

Li XH. Study on shaly sand irreducible water saturation calculation method. Master Thesis. Jilin University. 2006 (in Chinese).

Li DW, Zhang LH, Zhou KP, et al. Gas-water two-phase flow mechanism in visual microscopic pore model. J China Univ Pet (Ed Nat Sci). 2008;32(3):80-3 (in Chinese).

Li L, Li Z, Che Y. Influence of formation pressure fall on irreducible water saturation in sandstone gas reservoir. Xinjiang Pet Geol. 2010;31(6):626-8 (in Chinese).

Li HB, Guo HK, Li HJ, et al. Thickness analysis of bound water film in tight reservoir. Nat Gas Geosci. 2015;26(1):186-92 (in Chinese).

Looyestijn WJ. Distinguishing fluid properties and producibility from NMR logs. In: Proceedings of the 6th Nordic Symposium on Petrophysics. 2001; p. 1-9.

Majumdar A, Bhushan B. Role of fractal geometry in roughness characterization and contact mechanics of surfaces. J Tribol. 1990;112(2):205-16. https://doi.org/10.1115/1.2920243.

McKee CR, Bumb AC, Koenig RA. Stress-dependent permeability and porosity of coal. In: Fassett JE, editor. Geology and Coal-Bed Methane Resources of the northern San Juan Basin, Colorado and New Mexico. Denver: Rocky Mountain Association of Geologists; 1988. p. 142-53.

McKinney P, Rushing J, Sanders L. Applied reservoir characterization for maximizing reserve growth and profitability in tight gas sands: A paradigm shift in development strategies for low-permeability gas reservoirs. In: SPE gas technology symposium, society of petroleum engineers, 2002. https://doi.org/10.2118/75708-MS.

Melrose J. Valid capillary pressure data at low wetting-phase saturations (includes associated papers 21480 and 21618). SPE Reserv Eng. 1990;5(01):95-9. https://doi.org/10.2118/18331-PA.

Mo S, He S, Lei G, Gai S, Liu Z. Effect of the drawdown pressure on the relative permeability in tight gas: a theoretical and experimental study. J Nat Gas Sci Eng. 2015;24:264-71. https://doi. org/10.1016/j.jngse.2015.03.034.

Ofagbohunmi S, Chalaturnyk RJ, Leung JYW. Coupling of stressdependent relative permeability and reservoir simulation. In: SPE improved oil recovery symposium. Society of Petroleum Engineers, 2012. https://doi.org/10.7939/R3QH0J.

Ozhovan M. Dynamic uniform fractals in emulsions. J Exp Theor Phys. 1993;77(6):939-43.

She HY, Sleep BE. The effect of temperature on capillary pressuresaturation relationships for air-water and perchloroethylene-water systems. Water Resour Res. 1998;34(10):2587-97. https://doi. org/10.1029/98WR01199.

Taktak F, Rigane A, Boufares T, Kharbachi S, Bouaziz S. Modelling approaches for the estimation of irreducible water saturation and heterogeneities of the commercial Ashtart reservoir from the Gulf of Gabes, Tunisia. J Pet Sci Eng. 2011;78(2):376-83. https://doi. org/10.1016/j.petrol.2011.06.023.

Tan XH, Li XP, Liu JY, Zhang LH, Fan Z. Study of the effects of stress sensitivity on the permeability and porosity of fractal porous media. Phys Lett A. 2015;379(39):2458-65. https://doi. org/10.1016/j.physleta.2015.06.025.

Tian XF, Cheng LS, Li XL, et al. A new method to calculate relative permeability considering the effect of pore-throat distribution. $\mathrm{J}$ Shaanxi Univ Sci Technol. 2014;32(6):100-4 (in Chinese).

Tian XF, Cheng LS, Yan YQ, et al. An improved solution to estimate relative permeability in tight oil reservoirs. J Pet Explor Prod Technol. 2015;5(3):305-14. https://doi.org/10.1007/s1320 2-014-0129-7.

Wu QH, Bai B, Ma Y, Ok JT, Yin X, Neeves K. Optic imaging of two-phase-flow behavior in 1D nanoscale channels. SPE J. 2014;19(5):793-802. https://doi.org/10.2118/164549-PA.

Xu P, Yu B. Developing a new form of permeability and KozenyCarman constant for homogeneous porous media by means of 
fractal geometry. Adv Water Resour. 2008;31(1):74-81. https:// doi.org/10.1016/j.advwatres.2007.06.003.

Xu M, Zhu CQ, Tian YT, Rao S, Hu SB. Borehole temperature logging and characteristics of subsurface temperature in the Sichuan Basin. Chin J Geophys-CH. 2011;54(2):224-33. https://doi. org/10.1002/cjg2.1604.

Xu P, Qiu S, Yu B, Jiang Z. Prediction of relative permeability in unsaturated porous media with a fractal approach. Int J Heat Mass Transf. 2013;64:829-37. https://doi.org/10.1016/j.ijheatmasstrans fer.2013.05.003.

$\mathrm{Yu}$ BM. Fractal character for tortuous streamtubes in porous media. Chin Phys Lett. 2005;22(1):158. https://doi. org/10.1088/0256-307X/22/1/045.

Yu B, Cheng P. A fractal permeability model for bi-dispersed porous media. Int J Heat Mass Transf. 2002;45(14):2983-93. https://doi. org/10.1016/S0017-9310(02)00014-5.

Yu BM, Li JH. Some fractal characters of porous media. Fractals. 2001;9(3):365-72. https://doi.org/10.1142/S0218348X01000804.

Yu BM, Liu W. Fractal analysis of permeabilities for porous media. AIChE J. 2004;50(1):46-57. https://doi.org/10.1002/aic.10004.

Zhang C, Cheng Y, Zhang C. An improved method for predicting permeability by combining electrical measurements and mercury injection capillary pressure data. J Geophys Eng. 2016;14(1):132. https://doi.org/10.1088/1742-2140/14/1/132.
Zhang L, Tong J, Xiong Y, Zhao Y. Effect of temperature on the oilwater relative permeability for sandstone reservoirs. Int J Heat Mass Transf. 2017;105:535-48. https://doi.org/10.1016/j.ijhea tmasstransfer.2016.10.029.

Zheng Q, Yu BM, Duan YG, Fang QT. A fractal model for gas slippage factor in porous media in the slip flow regime. Chem Eng Sci. 2013;87:209-15. https://doi.org/10.1016/j.ces.2012.10.019.

Zhu S. Experiment research of tight sandstone gas reservoir stress sensitivity based on the capillary bundle mode. In: SPE annual technical conference and exhibition. Society of Petroleum Engineers, 2013. https://doi.org/10.2118/167638-STU.

Zhu L, Zhang C, Zhang C, Zhang Z, Zhou X, Zhu B. An improved theoretical nonelectric water saturation method for organic shale reservoirs. IEEE Access. 2019;7:51441-56. https://doi.org/10.1109/ ACCESS.2019.2912214. 